\title{
PENGARUH HUMAN CAPITAL DAN LINGKUNGAN KERJA TERHADAP LOYALITAS DOSEN YANG DIMEDIASI KEPUASAN KERJA: STUDI KASUS DOSEN UNIVERSITAS BUDI LUHUR
}

\author{
Yuni Kasmawati \\ Fakultas Teknologi Informasi Universitas Budi Luhur \\ Yuni.kasmawati@budiluhur.ac.id
}

\begin{abstract}
ABSTRAK
Perusahaan yang mampu bertahan, bersaing dan berkembang membutuhkan karyawan yang mempunyai ketrampilan dan kompetensi sesuai dengan kebutuhan agar mampu melaksanakan pekerjaan secara maksimal. Perkerjaan akan menjadi lebih efektif dan efisien dengan dukungan lingkungan kerja yang kondusif. Pengelolaan human capital diperlukan untuk menciptakan kepuasan karyawan yang pada akhirnya karyawan menjadi loyal. Karyawan yang loyal merupakan aset yang perlu dipertahankan untuk mencapai tujuan organisasi dan karyawan itu sendiri. Penelitian ini bertujuan untuk mengetahui peran human capital dan lingkungan kerja dalam menciptakan loyalitas kerja yang dimediasi oleh kepuasan karyawan dengan studi kasus dosen tetap Universitas Budi Luhur. Sampel sejumlah 80 responden diambil dari dosen yang aktif mengajar pada semester genap 2016/2017. Analisa data menggunakan path analysis atau analisis jalur Hasil penelitian ini menemukan bahwa human capital dan lingkungan kerja memberi pengaruh positif dan signifikan terhadap kepuasan kerja selanjutnya terdapat hubungan positif dan signifikan antara human capital, lingkungan dan kepuasan kerja terhadap loyalitas dosen. Lingkungan kerja memberi pengaruh yang paling besar terhadap loyalitas dosen. Hasil peneltian ini diharapkan dapat memberi informasi pihak manajemen bahwa human capital, lingkungan kerja dan kepuasan kerja berpengaruh terhadap loyalitas karyawan sehingga bisa dilakukan upaya-upaya untuk mengelola human capital dan menciptakan lingkungan kerja yang kondusif agar tercapai kepuasan kerja sehingga tercipta loyalitas dosen.
\end{abstract}

Kata Kunci : Human capital, lingkungan kerja, kepuasan karyawan, loyalitas karyawan

\section{A. LATAR BELAKANG}

Suatu organisasi mempunyai tujuan yang berbeda dan dibentuk berdasarkan visi dan misi yang telah ditetapkan. Untuk mencapai visi dan misi tersebut manusia menjadi faktor strategis sehingga suatu organisasi perlu menginvestasikan sumber daya untuk memastikan bahwa karyawannya memiliki informasi, keterampilan, dan kompetensi yang mereka butuhkan untuk bekerja secara efektif dalam lingkungan yang berubah dengan cepat dan kompleks. Investasi tersebut termasuk investasi sumber daya manusia melalui pemahaman human capital dalam meningkatkan kepuasan karyawan dan kinerja karyawan. Untuk itu organisasi perlu melihat kebutuhan karyawan dan memastikan 
kebijakan yang menyangkut human capital sesuai dengan tujuan organisasi dan karyawan.

Perusahaan yang ingin bertahan dalam jangka panjang, memerlukan karyawan yang loyal dalam melaksanakan kegiatan kerjanya, agar selalu melaksanakan pekerjaan dengan baik. Karyawan yang loyal merupakan aset perusahaan yang perlu dipertahankan dan ditingkatkan karena bisa memberikan keuntungan timbal balik. Karyawan yang mempunyai loyalitas akan dengan sadar melaksanakan kewajibannya dengan penuh tanggung jawab dengan mencurahkan semua kemampuannya untuk kemajuan organisasi. Dukungan terhadap program kerja organisasi dan bersedia berkorban untuk organisasi akan terlihat dari karyawan yang loyal.

Survei yang telah dilakukan Towers Watson tentang Global Workforce Study 2012 dengan menyertakan 29 negara dengan total responden sebanyak 32.000 karyawan termasuk Indonesia memperoleh kesimpulan bahwa karyawan di Indonesia mempunyai engagement atau loyalitas dan kesungguhan dalam bekerja sangat rendah. Faktor penyebabnya utamanya adalah salary atau gaji yang dirasa masih kurang sesuai. Faktor lainnya yaitu beban kerja, pengembangan karir, lokasi kerja, manfaat pensiun hingga hubungan kerja dengan atasannya (Tribunnews.Com, Jakarta). Hal yang sama juga didapatkan dari survei Gallup yang menyebutkan bahwa pekerja di Indonesia $80 \%$ dikategorikan sebagai not engaged di tempat kerja. Rinciannya hanya 13\% pekerja yang fully engaged, $76 \%$ not engaged, dan $11 \%$ actively disengaged. (http://portalhr.com/survei/gawatpekerja-di-indonesia-80-not-engaged-lantas-apa-solusinya)

Kepuasan kerja merupakan hal yang bersifat individual. Setiap orang memiliki tingkat kepuasan yang berbeda-beda sesuai keinginan dan sistem nilai yang dianut. Karyawan yang mempunyai kepuasan kerja tinggi akan senang melakukan pekerjaannya sehingga bekerja lebih akibatnya produktivitas kerjanya meningkat. Untuk itu kepuasan kerja memiliki arti yang sangat penting bagi perusahaan.

Lingkungan kerja dalam suatu organisasi perlu mendapat perhatian, karena mempunyai pengaruh langsung terhadap karyawan. Karyawan memerlukan lingkungan kerja yang kondusif agar kinerjanya dapat meningkat. Lingkuangan kerja dalam kondisi baik akan membuat karyawan bekerja secara aman, nyaman, sehat dan optimal. Dampak dari lingkungan kerja yang kondusif memerlukan waktu yang lebih lama untuk melihat hasilnya.

Tingkat persaingan antar perguruan tinggi di Indonesia tidak hanya persaingan antar perguruan tinggi lokal tetapi juga perguruan tinggi asing. Pengguna lulusan dan penyelenggara perguruan tinggi menuntut lulusan harus berpengetahuan, berketrampilan dan berkompetensi. Untuk mewujudkan hal tersebut peran human capital seorang dosen sangat diperlukan.

Universitas Budi Luhur merupakan organisasi di bidang pendidikan yang mempunyai tujuan mencetak manusia yang cerdas dan berbudi luhur. Untuk mencapai tujuan tersebut diperlukan pendidik yang tidak hanya berkompeten tetapi merasakan kepuasan dalam bekerja dan mempunyai loyaliats tinggi dengan dukungan lingkungan kerja yang kondusif mengingat adanya keuntungan timbal balik yang didapatkan antara organisasi dan karyawan. 
Penelitian ini akan melihat faktor yang mempengaruhi loyalitas dosen dari sisi internal yaitu human capital dosen dan dari sisi eksternal yaitu lingkungan kerja. Kedua sisi tersebut diharapkan mempengaruhi kepuasan kerja yang akhirnya akan berpengaruh pada loyalitas.

\section{B. LANDASAN TEORI}

\section{Loyalitas Karyawan}

Loyalitas karyawan merupakan bentuk kesetiaan karyawan yang tercermin dari kesediaan karyawan unntuk menjaga dan membela organisasi baik di dalam maupun di luar pekerjaannya dari rongrongan orang yang tidak bertanggung jawab (Hasibuan, 2011). Menurut (Natalie J Allen; Douglas B Grisaffe, 2001), loyalitas adalah keadaan psikologis yang menandai hubungan antara seorang karyawan dengan organisasi tempat mereka bekerja dan berimplikasi pada keputusan mereka untuk tetap berada di dalam organisasi. Sedangkan menurut Poerwopoespito (2004) mengartikan loyalitas pada pekerjaan sebagai sikap karyawan yang tercermin dengan mencurahkan segala kemampuan dan keahliannya, bertanggung jawab dalam melaksanakan tugas, bekerja dengan jujur, hubungan kerja dengan atasan maupun dengan rekan kerja baik, selalu menjaga citra perusahaan dan setia bekerja untuk waktu yang lebih lama.

Loyalitas karyawan mutlak diperlukan untuk kesuksesan sebuah organisasi. Suatu perusahaan yang mempunyai karyawan dengan loyalitas tinggi akan mudah untuk mencapai tujuan yang telah ditetapkan (Soegandhi, 2013). Indikasi menurunnya loyalitas karyawan menurut Nitisemito (1991) yaitu produktivitas kerja rendah, tingkat kehadiran menurun, perpindahan karyawan meningkat, karyawan mengalami kegelisahan, sering terjadi tuntutan dan mogok kerja.

Menurut Steers dan Porter (1983), faktor-faktor yang mempengaruhi loyalitas yaitu:

a. Karakteristik pribadi, meliputi jenis kelamin, usia, masa kerja, tingkat pendidikan, prestasi karyawan, ras dan kepribadian karyawan.

b. Karakteristik pekerjaan, meliputi stres kerja, kesempatan berinteraksi sosial, tantangan kerja, pengayaan kerja, kecocokan tugas, umpan balik tugas dan identifikasi tugas.

c. Karakteristik desain perusahaan, meliputi tingkat formalitas, keikutsertaan pengambilan keputusan, sentralisasi, fungsi pengendalian perusahaan, dan ketergantungan fungsional.

d. Pengalaman yang diperoleh dalam organisasi meliputi mempunyai sikap positif terhadap perusahaan, rasa aman yang timbul karena percaya pada perusahaan dan kepuasan karyawan yang dapat direalisasi oleh perusahaan.

Menurut Mathis (2005), aspek loyalitas meliputi :

a. Ketaatan atau kepatuhan, adalah kesanggupan karyawan dalam mentaati peraturan yang ditetapkan dan mentaati perintah pimpinan serta bersedia tidak melanggar larangan. Ketaatan mempunyai ciri-ciri mentaati peraturan dan ketentuan yang belaku, melaksanakan perintah 
atasan dengan baik, mentaati jam kerja dan memberi pelayanan sebaik-baikmya.

b. Bertanggung jawab, adalah kesediaan karyawan menyelesaikan pekerjaannya dengan baik, tepat waktu dan berani menanggung resiko atas keputusan yang diambil. Karyawan yang bertanggung jawab memiliki ciri-ciri tugas dikerjakan dengan baik dan waktu yang tepat, menyimpan dan memelihara barang-barang perusahaan dengan baik, tidak melempar kesalahan kepada orang lain.

c. Pengabdian adalah kontribusi pemikiran dan tenaga dengan ikhlas kepada perusahaan.

d. Kejujuran adalah keselarasan anatar perbuatan atau perkataan dengan kenyataan. Ciri-ciri karyawan jujur yaitu melaksanakan tugas dengan ikhlas, tidak menyalahgunakan wewenang dan memberi laporan hasil pekerjaan sesuai kenyataan.

Titik berat aspek loyalitas perusahan menurut Steers dan Porter (1983) yaitu karyawan mempunyai dorongan yang kuat menjadi anggota perusahaan, rasa ingin berusaha semaksimal mungkin untuk perusahaan serta kepercayaan dan penerimaan penuh nilai-nilai perusahaan.

Dalam penelitian ini dimensi loyalitas dosen menggunakan aspek menurut Mathis (2005) yaitu ketaatan dan kepatuhan, tanggung jawab, pengabdian dan kejujuran serta ditambahkan kiat kerja yang dicetuskan oleh pendiri Yayasan Pendidikan Budi Luhur.

\section{Kepuasan Kerja}

Karyawan yang bekerja pada sebuah organisasi selalu mengharapkan kepuasan di tempat kerja. Setiap individu mempunyai tingkat kepuasan yang berbeda-beda karena kepuasan kerja bersifat individual. Perbedaan tersebut karena nilai-nilai yang berlaku setiap individu berbeda-beda. Jika aspek dalam pekerjaan yang sesuai dengan keinginan individu banyak, maka tingkat kepuasan akan meningkat..

Kepuasan kerja adalah sikap umum seseorang terhadap perkerjaan yang menunjukkan perbedaan antara penghargaan yang diterima karyawan dengan jumlah yang diyakini diterima oleh karyawan (Wibowo, 2007). Menurut Umam (2010), kepuasan kerja adalah sikap positif karyawan terhadap perkerjaannya, yang ditimbulakan oleh penilaian terhadap situasi kerja. Pernilaian tersebut bisa dilakukan pada salah satu pekerjaannya.

Ada dua faktor yang mempengaruhui kepuasan kerja menurut Mangkunegara (2009) yaitu :

1. Faktor pegawai, yaitu kecerdasan (IQ), kecerdasan khusus, umur, jenis kelamin, kondisi fisik, pendidikan, pengalaman kerja, masa kerja, kepribadian, emosi, cara berfikir, persepsi, dan sikap kerja.

2. Faktor pekerjaan, yaitu jenis pekerjaan, struktur organisasi, pangkat (golongan), kedudukan, mutu pengawasan, jaminan finansial, kesempatan promosi jabatan, interaksi sosial, dan hubungan kerja.

Sedang menurut Robbins (2002) yang mempengaruhi kepuasan kerja adalah : 
1. Pekerjaan yang menantang. seseorang lebih menyukai pekerjaan yang menggunakan ketrampilan dan kemampuan dengan tugas yang beragam, serta umpan balik terhadap pekerjaannya.

2. Kesesuaian penghargaan yang diterima. Karyawan mengharapkan sistem pembayaran yang adil, tidak ambigu dan sesuai harapan.

3. Kondisi lingkungan kerja mendukung, kondisi lingkungan ini berhubungan dengan kenyamanan dan kemudahan karyawan dalam melakukan pekerjaan.

4. Hubungan interpersonal. Perilaku atasan merupakan faktor utama penentu kepuasan karyawan. Dalam menjaga hubungan interpersonal diperlukan saling menghargai, toleran, loyal, keakraban dan sikap terbuka.

Hasil penelitian yang dilakukan oleh (Masum, 2015) menyatakan bahwa faktor-faktor yang mempengaruhi kepuasan kerja yaitu paket kompensasi, dukungan pengawasan, keamanan kerja, peluang pelatihan dan pengembangan, kohesi tim, pertumbuhan karir, kondisi kerja, dan budaya organisasi dan kebijakan. Sedang hasil penelitian yang dilakukan oleh (Kazemzadeh, 2005) yaitu hubungan manajemen dan personil, hubungan antara karyawan, motivasi kerja, pendidikan, upah dan gaji, fasilitas kesejahteraan lainnya, komitmen karyawan, promosi jabatan, kinerja, sistem dan proses organisasi

menjelaskan bahwa faktor-faktor yang mempengaruhi kepuasan kerja yaitu

Seseorang yang merasakan kepuasan dalam bekerja maka produktivitas meningkat, tingkat kemangkiran karyawan dan turn over menurun (Robbins: 2003). Mengingat pentingnya kepuasan kerja karyawan bagi perusahaan, maka kepuasan kerja perlu ditingkatkan melalui (Riggio, 2012)

1. Perubahan struktur kerja, bisa dilakukan dengan job rotation maupun job enlargement.

2. Perubahan struktur pembayaran melalui pembayaran berdasar atas keahlian karyawan (skill-based pay), berdasar atas kinerjanya (merit pay) atau pembayaran berdasar atas keberhasilan kelompok (gainsharing).

3. Penjadwalan kerja secara fleksibel, dengan memadatkan pekerjaan mingguan atau dengan cara flextime (memberi jadwal karyawan sejumlah jam khusus perminggu)

4. Mengadakan program yang dapat meningkatkan kepuasan kerja misalnya profit sharing, health center dan employee sponsored child care.

Dalam penelitian ini dimensi kepuasan kerja yang digunakan sesuai dengan dimensi dalam penelitian (Masum, 2015) yaitu paket kompensasi, dukungan pengawasan, keamanan kerja, peluang pelatihan dan pengembangan, kohesi tim, pertumbuhan karir, kondisi kerja, dan budaya organisasi dan kebijakan.

\section{Human Capital}

Sumber daya manusia (SDM) merupakan salah satu faktor produksi yang penting dalam perusahaan. Tetapi sering pemimpin kurang menyadari kalau keuntungan perusahaan berasal dari SDM (human capital).

Intellectual capital terdiri dari social capital, human capital, and organizational capital (Patrick M. Wright, Benjamin B. Dunford, 2001). Dari ketiganya yang terpenting adalah human capital, karena human capital 
menentukan suatu perusahaan berhasil dalam menghadapi persaingan (Burr, 2002). Stewart et al dalam (Tjiptohadi Sawarjuwono, 2003) menjelaskan bahwa bahwa human capital menggambarkan kemampuan kolektif organisasi untuk mendapatkan solusi yang terbaik berdasarkan pengetahuan yang dimiliki oleh karyawan perusahaan.

Perusahaan harus proaktif mengingat peran SDM dalam perusahaan sangat besar. Perusahaan perlu menjadikan SDM-nya sebagai human capital yang harus diperhatikan dan secara terus-menerus dikembangkan sesuai kondisi lingkungan bisnis yang cepat berubah (Mayo, 2000).

Human capital merupakan aset inti suatu perusahaan yang terdiri dari kompetensi, pengetahuan, pengalaman, kecakapan, komitmen, sikap dan karakteristik individual (Chien Chang Yang, 2009). (Bontis, 2009), menambahkan bahwa modal manusia meliputi pengetahuan, kompetensi dan pengalaman.

Pengelolaan human capital untuk keberhasilan suatu perusahaan berhubungan dengan memperoleh, menganalisis dan melaporkan nilai tambah intellectual capital dan bagaimana pengelolannya dengan mengganggap human capital sebagai asset melalui investasi strategis dengan cara melibatkan karyawan, pembelajaran dan pengembangan program serta manajemen bakat (Armstrong, 2012).

Ada 4 peran human capital menurut (Ulrich, 1997) untuk membangun organisasi yang kuat, yaitu :

1. Management of Strategic human resources, sebagai strategi proses masa depan

2. Management of Transformation and Change, membuat organisasi tumbuh lebih produktif dengan tingkat keuntungan yang berkesinambungan.

3. Management of Firm Infrastructure, merekayasa ulang ke arah perbaikan organisasi.

4. Management of Employee Contribution, usaha peningkatan loyalitas karyawan.

Dalam penelitian ini, dimensi human capital menggunakan pendapat Bontis dan Serenko (2009) dimana modal manusia meliputi tiga faktor, yaitu kompetensi, pengalaman dan pengetahuan.

\section{Lingkungan Kerja}

Manusia selalu berusaha menyesyaikan dengan keadaan sekitarnya. Demikian juga dalam melakukan pekerjaannya, karyawan sebagai manusia tidak bisa dipisahkan dari keadaan tempat dimana karyawan bekerja. Selama bekerja, seorang karyawan akan berinterkasi dengan kondisi yang berbeda di lingkungan kerjanya.

Lingkungan kerja adalah sesuatu yang ada disekitar para pekerja dan yang mempengaruhi dirinya dalam menjalankan tugas-tugas yang dibebankan (Nitisemito, 1992). Selanjutnya menurut Sedarmayati (2001) lingkungan kerja merupakan keseluruhan alat perkakas dan bahan yang dihadapi, lingkungan sekitarnya dimana seseorang bekerja, metode kerjanya, serta pengaturan kerjanya baik sebagai perseorangan maupun sebagai kelompok. 
Kondisi lingkungan kerja dikatakan baik atau sesuai apabila manusia dapat melaksanakan kegiatan secara optimal, sehat, aman, dan nyaman. Kesesuaian lingkungan kerja dapat dilihat dampaknya dalam jangka waktu yang lama. Lebih jauh lagi, lingkungan-lingkungan kerja yang kurang baik dapat menuntut tenaga kerja dan waktu yang lebih banyak dan tidak mendukung diperolehnya rancangan sistem kerja yang efisien (Sedarmayanti, 2001). Lingkungan kerja dibedakan menjadi dua yaitu lingkungan fisik dan dan non fisik (Suwatno dan Priansa, 2011). Lingkungan fisik berupa ruang kerja, rancangan pekerjaan, kondisi lingkungan kerja dan tempat privasi serta lingkungan psikis meliputi pekerjaan yang berlebihan, sistem pengawasan buruk, frustasi, perubahan yang terjadi dalam segala bentuk ( jenis pekerjaan yang berubah, perubahan organisasi, pergantian pimpinan), perselisihan pribadi dan kelompok.

Dalam penelitian ini dimensi lingkungan kerja yang digunakan faktor-faktor yang mempengaruhi lingkungan kerja menurut Suwatno dan Priansa (2011).

Berdasarkan latar belakang, tinjauan pustaka dan peneltian sebelumnya maka disusun kerangka pemikiran sebagai berikut :

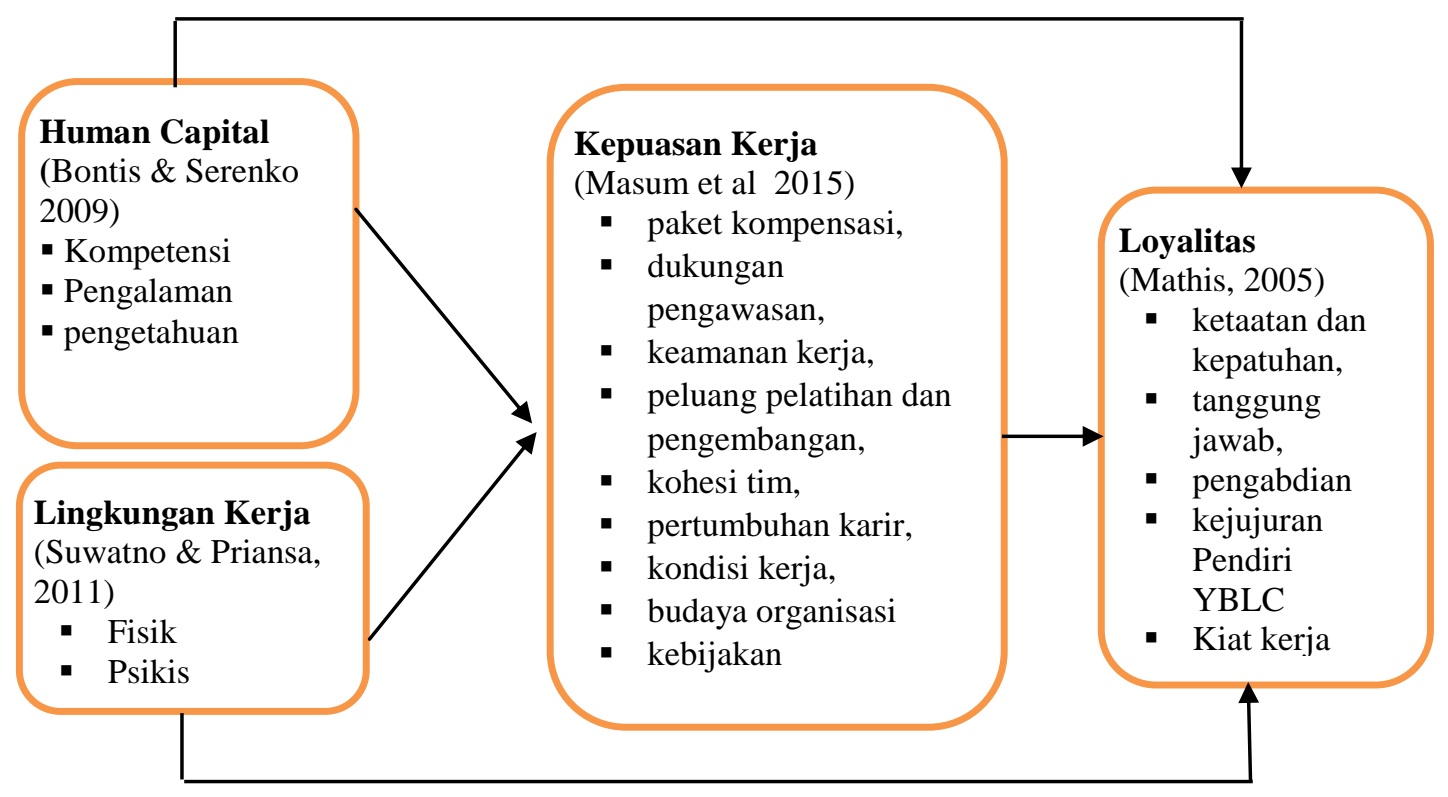

Gambar 1. Kerangka Pemikiran

\section{METODE PENELITIAN}

Metode yang digunakan didalam penelitian ini adalah metode Eksplanatori, yaitu penelitian yang bersifat menerangkan pengaruh variabel bebas terhadap variabel terikat. variabel bebas meliputi human capital, lingkungan kerja, variabel intervening yaitu kepuasan dosen sedang variabel terikatnya yaitu loyalitas dosen

Pengambilan sampel dengan metode purposive random sampling. Jumlah minimal sampel yang diambil yaitu 72 . Sampel diambil dari 252 dosen tetap yang aktif mengajar pada semester genap 2016/2017. Instrumen pengukuran variabel menggunakan skala Likert dengan skor 1 (sangat tidak setuju) sampai dengan 4 
(sangat setuju). Sebanyak 100 kuesioner dibagikan, tetapi yang dikembalikan sebanyak 80.

Pengolahan data meliputi uji validitas, uji reliabilitas, uji normalitas data, analisis statistis deskriptif dan anlisis regresi. Analisis jalur digunakan untuk melihat pengaruh langsung dan pengaruh tidak langsung antara variabel bebas dan terikat. Pengolahan data menggunakan software SPSS 19.

\section{HASIL DAN PEMBAHASAN}

\section{Gambaran Umum Organisasi}

Universitas Budi Luhur yang berada di bawah Yayasan Pendidikan Budi Luhur Cakti memiliki 2 program studi jenjang D3, 15 program studi strata satu (S1) dan 4 program pasca sarjana (S2), yaitu program D3 Unggulan Teknologi Informasi, Fakultas Teknologi Informasi, Fakultas Ekonomi, Fakultas Ilmu Komunikasi, Fakultas Ilmu Sosial dan Politik, Fakultas Teknik, Program Magister Manajemen, Program Magister Akuntasi, Program Magister Ilmu Komputer serta Program Magister Ilmu Komunikasi.

Universitas Budi Luhur mempunyai visi "Menjadi universitas unggul dengan standar mutu tertinggi, yang dilandasi kecerdasan dan keluhuran budi, ditopang teknologi informasi dan komunikasi, sedang misi Universitas Budi Luhur yaitu :

- Menyelenggarakan pendidikan berbasis kompetensi untuk menghasilkan lulusan yang unggul, cerdas dan berbudi luhur, serta mampu bersaing di dunia kerja.

- Memfasilitasi dan memotivasi sivitas akademika untuk mencapai penelitian bermutu.

- Melakukan kegiatan yang bermanfaat bagi kesejahteraan masyarakat luas sebagai bentuk nyata keluhuran budi.

- Menyelenggarakan kerjasama dengan institusi pemerintah maupun swasta dengan prinsip kesetaraan dan kemanfaatan.

- Menyelenggarakan pendidikan tinggi dengan dilandasi kecerdasan dan nilai-nilai keluhuran budi serta menerapkan tata kelola berbasis sistem mutu demi terwujudnya kredibilitas, transparansi, akuntabilitas, tanggung jawab dan keadilan.

- Meningkatkan kualitas hidup masyarakat Universitas Budi Luhur.

Pada semester genap 2016/2017 jumlah dosen tetap di Universitas Budi Luhur sebanyak 434 dosen dengan rincian Fakultas Ekonomi 114 dosen, Fakultas Teknik 19 dosen, Fakultas Ilmu Sosial dan Ilmu Politik 20 dosen, Fakultas Ilmu Komunikasi 88 dosen dan Fakultas Teknologi Informasi 193 dosen (https://forlap.ristekdikti.go.id, diakses 2 November 2017). Sedang gambaran mengenai masa kerja dosen yaitu : dosen dengan masa kerja $0-5$ tahun sebanyak $27,6 \%, 6-10$ tahun sebanyak 25,79\%, $11-15$ tahun sebanyak 22,17\%, $16-20$ tahun sebanyak 14,95\%, dan lebih dari 20 tahun sebanyak 9,5\%. Dari data tersebut dapat dilihat bahwa dosen yang mempunyai masa kerja di atas 10 tahun sebesar $46,61 \%$.

\section{Hasil}


Hasil uji validitas menunjukkan bahwa untuk variabel lingkungan kerja, human capital, kepuasan kerja dan loyalitas dosen pernyataan dalam kuesioner valid semua yang ditunjukkan dengan nilai Corrected Item-Total Correlation pada setiap pertanyaan mempunyai nilai di atas 0,3 (Setiaji, 2004: 59). Sedang hasil uji reliabilitas menunjukkan bahwa nilai Cronbach Alpha lebih besar dari 0,6 artinya kuesioner yang digunakan reliabel (Santosa dan Ashari, 2005).

Hasil uji normalitas data data menunjukkan bahwa data terdistribusi normal. Dalam penelitian ini tidak terjadi heteroskedastisitas dan model regresi dianggap memenuhi syarat. Uji multikolinieritas menunjukkan bahwa tidak terjadi korelasi antara variabel bebas.

\section{Statistik deskriptif}

Dari Tabel 1 dapat dijelaskan bahwa rata-rata skor variabel loyalitas sebesar 53,4125 dari 17 pertanyaan. Ini menggambarkan responden rata-rata memberi skor 3,14 setiap pernyataan (skala 1-4) yang berarti setuju dengan pernyataan. Semakin tinggi skor nilai menunjukkan loyalitas dosen semakin baik. Rata-rata skor variabel lingkungan kerja sebesar 37,2250 dari 11 pertanyaan. Ini menggambarkan responden rata-rata memberi skor 3,38 setiap pernyataan (skala 1-4) yang berarti setuju dengan pernyataan. Semakin tinggi skor nilai menunjukkan lingkungan kerja semakin baik. Rata-rata skor variabel human capital sebesar 36,5125 dari 11 pertanyaan. Ini menggambarkan responden rata-rata memberi skor 3,32 setiap pernyataan yang berarti setuju dengan pernyataan. Semakin tinggi skor nilai menunjukkan human capital semakin baik. Rata-rata skor variabel kepuasan sebesar 48,35 dari 16 pertanyaan. Ini menggambarkan responden rata-rata memberi skor 3,02 setiap pernyataan yang berarti setuju dengan pernyataan. Semakin tinggi skor nilai menunjukkan kepuasan dosen semakin baik. Nilai standar deviasi yang paling tinggi adalah variabel kepuasan kerja. Ini menunjukkan bahwa antar responden memberi nilai jawaban persepsi variabel tersebut lebih heterogen/beragam. 
Tabel 1. Statistik Deskriptif

Descriptive Statistics

\begin{tabular}{|l|r|r|r|}
\hline & Mean & Std. Deviation & \multicolumn{1}{|c|}{ N } \\
\hline Loyalitas & 53,4125 & 6,55009 & 80 \\
Lingk.Kerja & 37,2250 & 4,70920 & 80 \\
Hum.Capt & 36,5125 & 4,45794 & 80 \\
Kepuasan & 48,3500 & 6,57017 & 80 \\
\hline
\end{tabular}

\section{Analisis Jalur}

Persamaan struktural dalam penelitian ini :

1. $Y_{1}=\beta_{1} X_{1}+\beta_{2} X_{2}+\varepsilon_{1}$

2. $Y_{2}=\beta_{1} X_{1}+\beta_{2} X_{2}+\beta_{3} Y_{1}+\varepsilon_{2}$

Persamaan substruktur 1 yaitu $Y_{1}=\beta_{1} X_{1}+\beta_{2} X_{2}+\varepsilon_{1}$

a. Analisi Regresi

Dari tabel 2 dapat dilihat bahwa nilai $\mathrm{R}^{2}$ sebesar 0,263 yang menunjukkan bahwa variabilitas kepuasan kerja dapat diterangkan oleh variabel human capital dan lingkungan kerja sebesar 26,3\%, sedangkan 73,7\% disebabkan oleh faktor lain. Nilai koefisien korelasi sebesar 0,513 menunjukkan hubungan antara variabel human capital dan lingkungan kerja kuat (Sarwono,2007).

Tabel 2. Model Summary Variabel Human Capital dan Lingkungan Kerja terhadap Kepuasan Kerja

Model Summary

\begin{tabular}{|c|c|c|c|c|c|c|c|c|c|}
\hline \multirow[b]{2}{*}{$\begin{array}{l}\text { Mode } \\
1\end{array}$} & \multirow[b]{2}{*}{$\mathrm{R}$} & \multirow[b]{2}{*}{$\begin{array}{c}\mathrm{R} \\
\text { Square }\end{array}$} & \multirow[b]{2}{*}{$\begin{array}{l}\text { Adjusted R } \\
\text { Square }\end{array}$} & \multirow[b]{2}{*}{$\begin{array}{l}\text { Std. Error of } \\
\text { the Estimate }\end{array}$} & \multicolumn{5}{|c|}{ Change Statistics } \\
\hline & & & & & $\begin{array}{l}\text { R Square } \\
\text { Change }\end{array}$ & $\begin{array}{c}\mathrm{F} \\
\text { Change }\end{array}$ & df1 & df 2 & $\begin{array}{c}\text { Sig. F } \\
\text { Change }\end{array}$ \\
\hline 1 &, $513^{\mathrm{a}}$ & ,263 & ,244 & 5,71214 & ,263 & 13,758 & 2 & 77 &, 000 \\
\hline
\end{tabular}

a. Predictors: (Constant), Hum.Capt, Lingk.Kerja

Berdasarkan Tabel 3 menunjukkan bahwa perhitungan angka signifikansi sebesar $0,000<0,05$ maka $\mathrm{H}_{0}$ ditolak dan $\mathrm{H}_{1}$ diterima. Artinya ada hubungan linier antara human capital dan lingkungan kerja terhadap kepuasan dosen dan model regresi yang dibuat layak.

Tabel 3. Hasil Uji F Variabel Variabel Human Capital dan Lingkungan Kerja terhadap Kepuasan Lerja

ANOVA $^{b}$

\begin{tabular}{|c|c|c|c|c|c|}
\hline Model & Sum of Squares & $\mathrm{df}$ & Mean Square & $\mathrm{F}$ & Sig. \\
\hline 1 Regression & 897,803 & 2 & 448,902 & 13,758 &, $000^{\mathrm{a}}$ \\
\hline Residual & 2512,397 & 77 & 32,629 & & \\
\hline Total & 3410,200 & 79 & & & \\
\hline
\end{tabular}

a. Predictors: (Constant), Hum.Capt, Lingk.Kerja

b. Dependent Variable: Kepuasan

Tabel 4. Hasil Uji t Variabel Human Capital dan Lingkungan Kerja terhadap Kepuasan Kerja

Coefficients $^{\mathrm{a}}$ 


\begin{tabular}{|c|c|c|c|c|c|}
\hline \multirow[b]{2}{*}{ Model } & \multicolumn{2}{|c|}{ Unstandardized Coefficients } & \multirow{2}{*}{$\frac{\text { Standardized Coefficients }}{\text { Beta }}$} & \multirow[b]{2}{*}{$\mathrm{t}$} & \multirow[b]{2}{*}{ Sig. } \\
\hline & $\mathrm{B}$ & Std. Error & & & \\
\hline 1 (Constant) & 16,289 & 6,153 & & 2,648 & 010 \\
\hline Lingk.Kerja & ,370 &, 151 & ,26 & 2,451 & 017 \\
\hline Hum.Capt &, 500 &, 160 & ,34 & 3,134 &, 002 \\
\hline
\end{tabular}

a. Dependent Variable: Kepuasan

Hasil uji t seperti pada tabel 4 menunjukkan bahwa ada hubungan linier yang signifikan (nilai signifikansi 0,01<0,05) antara lingkungan kerja dengan kepuasan kerja. Besarnya pengaruh lingkungan kerja sebesar 0,266 atau $26,6 \%$. Terdapat hubungan yang linier dan signifikan (nilai signifikansi $0,002<0,05)$ antara human capital dengan kepuasan kerja. Besarnya pengaruh human capital sebesar 0,34 atau $34 \%$.

b. Analisis Korelasi

Analisis korelasi antara variabel human capital dan lingkungan kerja terhadap kepuasan kerja pada tabel 5 menunjukkan bahwa:

1. Korelasi antara lingkungan kerja dengan kepuasan sebesar 0,411 dikategorikan cukup kuat dan searah dan signifikan (nilai signifikansi $0,00<0,05)$. Artinya bahwa jika kondisi lingkungan kerja baik maka kepuasan dosen akan tinggi.

2. Korelasi antara human capital dengan kepuasan kerja sebesar 0,454 yang dikategorikan cukup kuat dan searah dan signifikan (nilai signifikansi $0,00<0,005)$. Artinya bahwa jika human capital meningkat maka kepuasan dosen akan tinggi.

3. Korelasi antara lingkungan kerja dengan human capital sebesar 0,430 dikategorikan cukup kuat dan searah dan signifikan (nilai signifikansi $0,00<0,05)$. Artinya bahwa jika kondisi lingkungan kerja baik maka human capital meningkat.

Tabel 5. Korelasi antara Variabel Human Capital dan Lingkungan Kerja terhadap Kepuasan Dosen

Correlations

\begin{tabular}{|ll|r|r|r|}
\hline & & Lingk.Kerja & Hum.Capt & Kepuasan \\
\hline Lingk.Kerja & Pearson Correlation & 1 &, $430^{* *}$ &, $411^{* *}$ \\
& Sig. (2-tailed) & &, 000 &, 000 \\
& $\mathrm{~N}$ & 80 & 80 & 80 \\
\hline Hum.Capt & Pearson Correlation &, $430^{* * *}$ & 1 &, $454^{* * *}$ \\
& Sig. (2-tailed) &, 000 & &, 000 \\
& $\mathrm{~N}$ & 80 & 80 & 80 \\
\hline Kepuasan & Pearson Correlation &, $411^{* * *}$ &, $454^{* * *}$ & 1 \\
& Sig. (2-tailed) &, 000 &, 000 & \\
& $\mathrm{~N}$ & 80 & 80 & 80 \\
\hline
\end{tabular}

Persamaan substruktur 2 yaitu $Y_{2}=\beta_{1} X_{1}+\beta_{2} X_{2}+\beta_{3} Y_{1}+\varepsilon_{2}$

a. Analisi Regresi

Tabel 6 menunjukkan bahwa besarnya nilai $\mathrm{R}^{2}$ adalah 0,316 artinya variabilitas loyalitas dosen dapat diterangkan oleh variabel human capital, lingkungan kerja dan kepuasan sebesar 31,6\%, sedangkan 68,4\% disebabkan 
oleh faktor lain. Koefisien korelasi sebesar 0,562 menunjukkan hubungan antara human capital, lingkungan kerja dan kepuasan kerja terhadap loyalitas kuat (Sarwono, 2007).

Hasil uji $\mathrm{F}$ pada tabel 7 menunjukkan tingkat signifikansi sebesar $0,000<0,05$, maka dapat disimpulkan Ho ditolak dan $\mathrm{H}_{1}$ diterima. Artinya ada hubungan linier antara variabel lingkungan kerja, human capital, kepuasan kerja terhadap loyalitas dosen. Dengan demikian model regresi yang dibangun pada penelitian ini sudah layak

Tabel 6. Model Summary Variabel Human Capital, Lingkungan Kerja dan Kepuasan Kerja terhadap Loyalitas Dosen Model Summary

\begin{tabular}{|c|c|c|c|c|c|c|c|c|c|}
\hline \multirow[b]{2}{*}{ Model } & \multirow[b]{2}{*}{$\mathrm{R}$} & \multirow[b]{2}{*}{$\begin{array}{c}\mathrm{R} \\
\text { Square }\end{array}$} & \multirow[b]{2}{*}{$\begin{array}{l}\text { Adjusted R } \\
\text { Square }\end{array}$} & \multirow[b]{2}{*}{$\begin{array}{l}\text { Std. Error of the } \\
\text { Estimate }\end{array}$} & \multicolumn{5}{|c|}{ Change Statistics } \\
\hline & & & & & $\begin{array}{l}\text { R Square } \\
\text { Change }\end{array}$ & $\begin{array}{c}\mathrm{F} \\
\text { Change }\end{array}$ & df1 & df 2 & $\begin{array}{c}\text { Sig. F } \\
\text { Change }\end{array}$ \\
\hline 1 &, $562^{\mathrm{a}}$ & ,316 & ,289 & 5,52441 &, 316 & 11,686 & 3 & 76 &, 000 \\
\hline
\end{tabular}

a. Predictors: (Constant), Kepuasan, Lingk.Kerja, Hum.Capt

Tabel 7. Hasil Uji F Variabel Variabel Human Capital, Lingkungan Kerja dan Kepuasan Lerja terhadap Loyalitas Dosen

\begin{tabular}{|c|c|c|c|c|c|}
\hline \multicolumn{6}{|c|}{ ANOVA $^{b}$} \\
\hline Model & Sum of Squares & $\mathrm{df}$ & Mean Square & $\mathrm{F}$ & Sig. \\
\hline 1 Regression & 1069,938 & 3 & 356,646 & 11,686 &, $000^{\mathrm{a}}$ \\
\hline Residual & 2319,449 & 76 & 30,519 & & \\
\hline Total & 3389,388 & 79 & & & \\
\hline
\end{tabular}

Hasil uji t pada tabel 8 menunjukkan bahwa :

1. Hubungan antara lingkungan kerja dengan loyalitas dosen mempunyai nilai signifikansi sebesar $0,011<0,005$, artinya ada hubungan linier signifikan antara lingkungan kerja dengan loyalitas dosen. Besarnya pengaruh lingkungan kerja terhadap loyalitas dosen yaitu 0,285 atau $28,5 \%$

2. Hubungan antara human capital dengan loyalitas dosen mempunyai nilai signifikansi sebesar $0,017<0,05$ artinya ada hubungan linier signifikan antara human capital dengan loyalitas dosen. Besarnya pengaruh human capital terhadap loyalitas dosen yaitu 0,271 atau 27,1\%.

3. Hubungan antara kepuasan kerja dengan loyalitas dosen mempunyai nilai signifikansi sebesar 0,179>0,005 artinya tidak ada hubungan linier signifikan antara lingkungan kerja dengan loyalitas dosen. Besarnya pengaruh lingkungan kerja terhadap loyalitas dosen yaitu 0,150 atau $15 \%$ dianggap tidak signifikan.

Tabel 8. Hasil Uji t Variabel Lingkungan Kerja, Human Capital, Kepuasan Kerja terhadap Loyalitas Dosen Coefficients $^{\mathrm{a}}$ 


\begin{tabular}{|c|c|c|c|c|c|}
\hline \multirow[b]{2}{*}{ Model } & \multicolumn{2}{|c|}{ Unstandardized Coefficients } & \multirow{2}{*}{$\frac{\text { Standardized Coefficients }}{\text { Beta }}$} & \multirow[b]{2}{*}{$\mathrm{t}$} & \multirow[b]{2}{*}{ Sig. } \\
\hline & $\mathrm{B}$ & Std. Error & & & \\
\hline 1 (Constant) & 16,884 & 6,215 & & 2,716 & ,008 \\
\hline Lingk.Kerja & 396 & , 152 & ,28 & 2,611 & ,011 \\
\hline Hum.Capt & ,399 &, 164 &, 27 & 2,431 & ,017 \\
\hline Kepuasan & 149 &, 110 & , 15 & 1,356 & , 179 \\
\hline
\end{tabular}

a. Dependent Variable: Loyalitas

b. Analisi korelasi

Korelasi antara human capital, lingkungan kerja dan kepuasan dosen terhadap loyalitas dosen pada Tabel 9 menunjukkan bahwa :

1. Korelasi antara lingkungan kerja dengan loyalitas dosen sebesar 0,463 dikategorikan cukup kuat dan searah dan signifikan (nilai signifikansi $0,00<0,05)$. Artinya bahwa jika kondisi lingkungan kerja baik maka loyalitas dosen akan tinggi.

2. Korelasi antara human capital dengan loyalitas dosen sebesar 0,462 dikategorikan cukup kuat dan searah dan signifikan (nilai signifikansi $0,00<0,05)$. Artinya bahwa jika human capital baik maka loyalitas dosen akan tinggi

3. Korelasi antara kepuasan kerja dengan loyalitas dosen sebesar 0,390 dikategorikan cukup kuat dan searah dan signifikan (nilai signifikansi $0,00<0,05)$. Artinya bahwa jika kepuasan kerja miningkat maka loyalitas dosen akan meningkat pula.

Tabel 9. Korelasi antara Human Capital, Lingkungan Kerja dan Kepuasan Kerja terhadap Loyalitas Dosen

\begin{tabular}{|ll|r|r|r|r|}
\multicolumn{5}{c|}{ Correlations } \\
\hline Lingk.Kerja & Lingk.Kerja & Hum.Capt & Kepuasan & Loyalitas \\
& Pearson Correlation & 1 &, $430^{* *}$ &, $411^{* * *}$ &, $463^{* * *}$ \\
& Sig. (2-tailed) & &, 000 &, 000 &, 000 \\
& $\mathrm{~N}$ & 80 & 80 & 80 & 80 \\
\hline Hum.Capt & Pearson Correlation &, $430^{* * *}$ & 1 &, $454^{* * *}$ &, $462^{* *}$ \\
& Sig. (2-tailed) &, 000 & &, 000 &, 000 \\
& $\mathrm{~N}$ & 80 & 80 & 80 & 80 \\
\hline Kepuasan & Pearson Correlation &, $411^{* * *}$ &, $454^{* *}$ & 1 &, $390^{* * *}$ \\
& Sig. (2-tailed) &, 000 &, 000 & &, 000 \\
& $\mathrm{~N}$ & 80 & 80 & 80 & 80 \\
\hline Loyalitas & Pearson Correlation &, $463^{* * *}$ &, $462^{* *}$ &, $390^{* * *}$ & 1 \\
& Sig. (2-tailed) &, 000 &, 000 &, 000 & \\
& $\mathrm{~N}$ & 80 & 80 & 80 & 80 \\
\hline
\end{tabular}

Besarnya pengaruh lansung dan tidak langsung dan pengaruh total dapat dilihat pada Tabel 11 berikut ini.

Tabel 11. Pengaruh Langsung dan Tidak Langsung

\begin{tabular}{|l|c|c|c|}
\hline \multirow{2}{*}{ Variabel } & \multicolumn{3}{|c|}{ Pengaruh } \\
\cline { 2 - 4 } & Langsung & Tidak Langsung & Total \\
\hline $\mathrm{X}_{1} \rightarrow \mathrm{Y}_{1}$ & 0,340 & & 0,040 \\
\hline
\end{tabular}




\begin{tabular}{|c|c|c|c|}
\hline $\mathrm{X}_{2} \rightarrow \mathrm{Y}_{1}$ & 0,266 & & 0,266 \\
\hline $\mathrm{Y}_{1} \rightarrow \mathrm{Y}_{2}$ & 0,150 & & 0,150 \\
\hline $\mathrm{X}_{1} \rightarrow \mathrm{Y}_{2}$ & 0,271 & 0,051 & 0,322 \\
\hline $\mathrm{X}_{2} \rightarrow \mathrm{Y}_{2}$ & 0,285 & 0,0399 & 0,3249 \\
\hline
\end{tabular}

Dari hasil analisis regresi substruktur 1 dan dan 2 dapat dirangkum seperti pada gambar 2 di bawah ini.

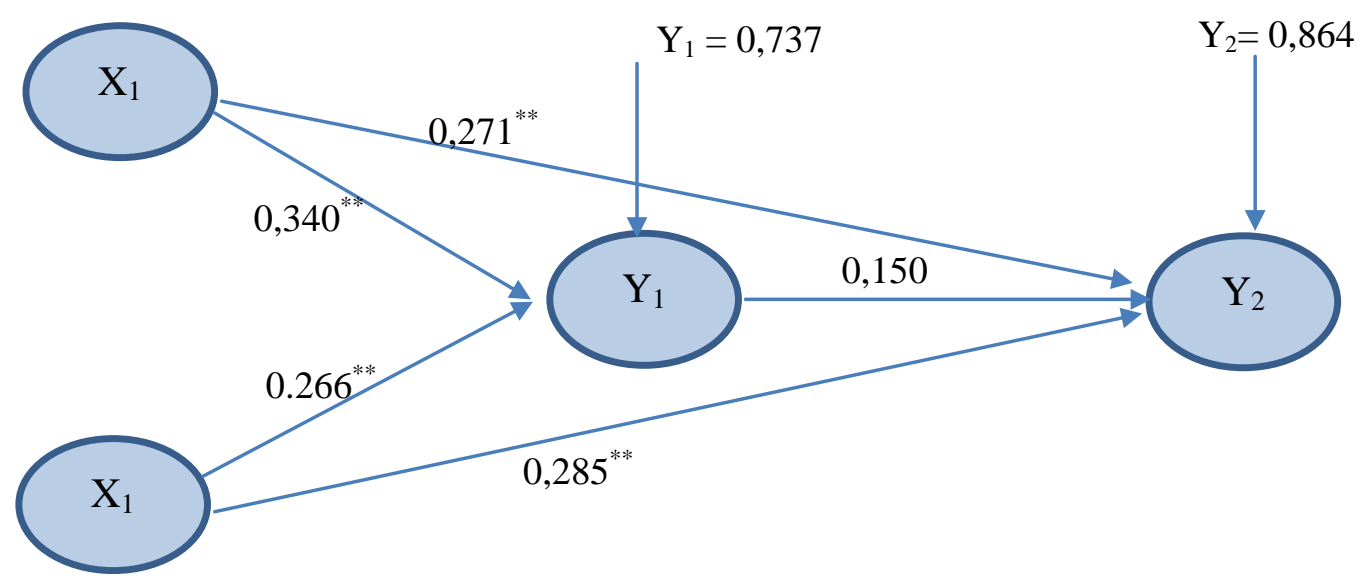

Gambar 2. Diagram Jalur

Sehingga persamaan struktural untuk model penelitian yaitu :

$$
\begin{aligned}
& \mathrm{Y}_{1}=0,340 \mathrm{X}_{1}+0,266 \mathrm{X}_{2}+\varepsilon_{1} \\
& \mathrm{Y}_{2}=0,271 \mathrm{X}_{1}+0,285 \mathrm{X}_{2}+0,150 \mathrm{Y}_{1}+\varepsilon_{2}
\end{aligned}
$$

\section{Pembahasan}

1. Pengaruh human capital dan lingkungan kerja terhadap kepuasan kerja.

Variabel human capital dan lingkungan kerja baik secara simultan maupun secara bersama-sama berpengaruh signifikan terhadap kepuasan kerja. Hasil penelitian sejalan dengan hasil penelitian yang dilakukan oleh Elisaveta Gjorgji Sardzoska dan Thomas Li-PingTang (2012), Al-Hamdan et al (2017) bahwa lingkungan kerja berpengaruh signifikan terhadap kepuasan kerja. Hasil yang sama seperti penelitian yang dilakukan oleh Masum, et al (2015) bahwa kondisi kerja dan keamanan kerja merupakan faktor yang paling berpengaruh terhadap kepuasan kerja. Pengaruh yang signifikan pada variabel human capital terhadap kepuasan kerja sejalan dengan hasil penelitian Hooi Lai Wan (2007) dimana perusahaan yang mementingkan human capital development mempunyai kepuasan yang lebih tinggi.

Variabel human capital memiliki pengaruh yang lebih besar (0.340) dari pada lingkungan kerja (0.266). Hal ini ditunjukkan dengan kondisi dosen yang ada di UBL pada umumnya mengajar mata kuliah sesuai dengan bidang ilmu yang dimiliki, mampu menciptakan hubungan yang edukatif selama perkuliahan dan mampu melihat perbedaan antar mahasiswa. Disamping 
mempunyai kompetensi tersebut, dosen UBL memiliki pengalaman dalam melakukan pekerjaan dan mempunyai pengetahuan serta kemampuan dalam berinovasi dan responsif terhadap perubahan lingkungan. Hal yang menjadi perhatian terhadap dosen UBL yaitu perlu peningkatan daya saing dosen dengan perguruan tinggi lain serta perlu dimotivasi untuk bergabung dan aktif dengan organisasi profesional di lingkungan dosen.

Lingkungan kerja di UBL secara fisik sudah memadai. Misalnya dari segi perlengkapan kerja yang sudah memadai sehingga membantu kelancaran perkerjaan dan dari segi kebersihan ruang kerja membuat dosen nyaman dalam bekerja. Lingkungan kerja non fisik misalnya kerja sama antar teman membuat pekerjaan menjadi lebih mudah dan cepat selesai serta hubungan baik dengan atasan dapat meningkatkan semangat kerja. Yang perlu menjadi perhatian sehubungan dengan atasan yaitu masih diperlukannya pemberian kebebasan kepada dosen dalam berpendapat untuk menyelesaikan pekerjaan, masih dibutuhkannya bimbingan, arahan dan dorongan dalam menyelesaikan tugas serta pujian kepada dosen yang mampu menyelesaikan pekerjaan sesuai target yang ditetapkan. Penataan ruang kerja juga perlu menjadi perhatian agar dosen lebih nayaman dalam bekerja.

2. Menganalisis human capital dan lingkungan kerja berpengaruh terhadap loyalitas dosen dengan mediasi kepuasan dosen.

Variabel human capital, lingkungan kerja dan kepuasan kerja secara simultan berpengaruh signifikan terhadap loyalitas dosen. Secara parsial human capital dan lingkungan kerja berpengaruh signifikan terhadap loyalitas dosen, tetapi variabel kepuasan kerja berpengaruh tidak signifikan. Variabel kepuasan kerja belum memediasi pengaruh human capital dan lingkungan kerja terhadap loyalitas dosen dilihat dari koefisien jalur lebih rendah (0.150) dan dari pada variabel human capital $(0.271)$ dan variabel lingkungan kerja $(0,285)$.

Secara umum yang mendukung kepuasan kerja dosen UBL antar lain evaluasi dari mahasiswa yang diterima dosen setiap semester, peluang luas yang diberikan oleh Yayasan Budi Luhur Cakti untuk meningkatkan kemampuan dosen, pelatihan yang diberikan kepada dosen sesuai dengan kebutuhan dosen, komunikasi timbal balik antar akademisi sudah baik, serta tuntutan untuk berikir inovatif dan berani mengambil keputusan. Kondisi-kondisi yang perlu mendapat perhatian sehubungan dengan kepuasan kerja yaitu kompensasi berupa gaji dibandingkan dengan perguruan tinggi lain yang dirasa masih timpang. Hal ini memungkinkan penyebab pengaruh kepuasan kerja terhadap loyalitas tidak signifikan. Mengingat penelitian yang dilakukan oleh Masum, et al (2015) menyimpulkan bahwa faktor yang paling berpengaruh terhadap kepuasan kerja adalah paket kompensasi. Hal lain yang memberi kontribusi terhadap ketidakpuasan dosen yaitu pola komunikasi di UBL yang dirasakan dosen belum kondusif, kebijakan evaluasi kinerja dosen dilakukan belum transparan serta fasilitas kesejahteraan yang belum sesuai harapan.

Loyalitas dosen UBL pada umumnya dapat dilihat dari aspek kejujuran dalam meraka menyelesaikan pekerjaan, dosen tidak menyelewengkan wewenang yang telah diberikan. Kiat kerja dosen yang menunjukkan loyalitas dosen seperti 
mampu memotivasi mahasiswa dalam belajar, tidak pernah menimbulkan masalah di lingkungan kampus serta upaya pendekatan antar sesama rekan kerja yang dapat memudahkan dalam penyelesaian pekerjaan. Mentaati peraturan tanpa pengawasan belum menjadi budaya di lingkungan dosen UBL, begitu juga dengan kedisiplinan ketepatan waktu kerja. Disamping itu kebiasaan memberi masukan kepada atasan baik diminta maupun tidak belum menjadi kebiasaan. Lama kerja dosen dan kepercayaan dosen terhadap UBL belum menjadi pendorong untuk meningkatkan loyalitas dosen.

\section{E. KESIMPULAN DAN SARAN}

\section{Kesimpulan}

1. Terdapat pengaruh positif dan signifikan antara variabel human capital dan lingkungan kerja terhadap kepuasan kerja. Ini menunjukkan bahwa semakin tinggi human capital dan semakin baik lingkungan kerja akan meningkatkan kepuasan kerja. Variabel human capital memberi pengaruh yang lebih besar dari pada lingkungan kerja terhadap kepuasan kerja.

2. Terdapat hubungan positif yang kuat antara human capital dan lingkungan kerja dengan kepuasan kerja dengan nilai koefisien sebesar 0,513 dan koefisien determinasi sebesar 0,263

3. Terdapat pengaruh positif dan signifikan antara variabel human capital, lingkungan kerja dan kepuasan terhadap loyalitas kerja. Ini menunjukkan bahwa semakin tinggi human capital dan semakin baik lingkungan kerja serta kepuasan kerja yang dirasakan semakin tinggi maka loyalitas dosen akan semakin tinggi.

4. Secara parsial variabel lingkungan kerja dan human capital berpengaruh signifikan terhadap loyalitas dosen. Tetapi variabel kepuasan tidak berpengaruh signifikan. Variabel lingkungan kerja memberi pengaruh paling besar diantara variabel human capital dan kepuasan kerja.

5. Terdapat hubungan positif yang kuat antara human capital, lingkungan dan kepuasan kerja terhadap loyalitas dosen dengan nilai koefisien sebesar 0,562 dan koefisien determinasi sebesar 0,316

\section{Saran}

Untuk meningkatkan peran human capital, lingkungan kerja kondusif, kepuasan kerja dan loyalitas dosen, ada beberapa hal yang perlu mendapat perhatian yaitu : 1) Mendorong dosen untuk bergabung dan berperan aktif dalam organisasi profesional sesuai bidang ilmunya sehingga mampu bersaing dengan dosen dari perguruan tinggi lain dan lebih percaya diri. 2) Mengirim dosen ke berbagai pelatihan/workshop/seminar sesuai bidang ilmu dan pekerjaan agar dosen mampu mengerjakan sesuai standar yang ditetapkan UBL dan DIKTI. 3) Fasilitas dan sarana untuk berbagi pengetahuan, informasi dan pertemuan ilmiah perlu ditingkatkan. 4) Bimbingan, arahan, dukungan dan pujian serta reward bagi dosen yang mampu mencapai target sesuai standar. 5) Dosen diberi kebebasan berpendapat dalam menyelesaikan pekerjaan. 6) Penataan ruang kerja agar lebih 
nyaman dam lebih luas. 7) Peninjauan kembali struktur pembayaran berdasar keahlian, kinerja atau keberhasilan kelompok. 8) Pola komunikasi antar manajemen dengan dosen maupun dosen dengan dosen perlu diperbaiki agar tidak tumpang tindih dalam menjalankan tugas dosen. 9) Perbaikan fasilitas kesejahteraan. 10) Aturan dan kebijakan evaluasi kinerja dosen perlu diperjelas untuk pertimbangan reward dan punishment. 11) Transparansi terhadap informasi dan persyaratan terhadap peluang promosi sehingga semua dosen mempunyai kesempatan yang sama. 12) Penjadwalan kerja yang fleksibel atau memberi jadwal dosen sejumlah jam khusus perminggu. 13) Peninjauan kembali terhadap aturan dan metode pengawasan kinerja dosen untuk menumbuhkan kedisiplinan dan keikhlasan kerja tanpa pengawasan yang ketat. 14) Memberi peluang kepada dosen untuk berpendapat dan masukan-masukan sehingga timbul rasa memiliki.15) Peningkatan kepercayaan dosen terhadap UBL melalui transparansi aturan, prosedur, informasi, evaluasi kinerja, reward dan punishment. 


\section{DAFTAR PUSTAKA}

Armstrong, M. (2012). Armstrong's Handbook of Human Resource Management Practice (12th ed). London: Kogan Page. Retrieved from http://libgen.io/book/index.php?md5=BF53926315DF3A90C5DF0F57043F EFC7

Bontis, N. A. S. (2009). A Causal Model of Human Capital Antecedents and Consequents in The Financial Services Industry. Journal of Intellectual Capital, $10 \quad$ (1), 53-69. https://doi.org/https://doi.org/10.1108/14691930910922897

Burr, R. A. G. (2002). Intellectual Capital: More Than the Interaction of Competence x Commitment. Australian Journal of Management, 27(1), 7787. https://doi.org/https://doi.org/10.1177/031289620202701S09

Chien Chang Yang, C. Y. Y. L. (2009). Does Intellectual Capital Mediate The Relationship between HRM and Organizational Performance? Perspective of A Healthcare Industry in Taiwan. The International Journal of Human Resource Management, 20(9), 1965-1984. https://doi.org/https://doi.org/10.1080/09585190903142415

Hasibuan, Malayu S.P., 2011. Manajemen Sumber Daya Manusia. Bumi Aksara, Jakarta

Kazemzadeh;, R. B. ;Mahd. B. (2005). Determination of Critical Factors on Employee Satisfaction - A case study on a Financial Institute. In Proceedings. 2005 IEEE International Engineering Management Conference, 2005. St. John's, Newfoundland \& Labrador, Canada, Canada: IEEE. https://doi.org/10.1109/IEMC.2005.1559079

Mangkunegara. Anwar Prabu 2009. Manajemen Sumber Daya Manusia. Bandung: PT. Remaja Rosdakarya

Masum, A. K. M. M. A. K. A. L.-S. B. (2015). Determinants of Academics' Job Satisfaction: Empirical Evidence from Private Universities in Bangladesh. PLOS ONE, 1-15. https://doi.org/https://doi.org/10.1371/journal.pone.0117834

Mathis, R. L. Jackson, J. H. 2005. Manajeman Sumber Daya Manusia. Jilid 2. Jakarta: Salemba Empat

Mayo, A. (2000). The Role of Employee Development in The Growth of Intellectual Capital. Personnel Review, 29(4), 521-533. https://doi.org/https://doi.org/10.1108/00483480010296311

Natalie J Allen; Douglas B Grisaffe. (2001). Employee Commitment to The Organization and Customer Reactions: Mapping The Linkages. Human Resource Management Review, 11(3), 209-236. https://doi.org/https://doi.org/10.1016/S1053-4822(00)00049-8

Nitisemito, Alex S. 1992. Manajemen Personalia. Ghaila Indonesia: Jakarta.

Patrick M. Wright, Benjamin B. Dunford, S. A. S. (2001). Human Resources and The Resource Based View of The Firm. Journal of Management, 27(6), 701721. https://doi.org/https://doi.org/10.1177/014920630102700607

Poerwopoespito, FX Oerip S. 2004. Mengatasi Krisis Manusia di Perusahaan: Solusi Melalui Pengembangan Sikap Mental. Jakarta: Grasindo 
Riggio, R. (2012). Introduction to Industrial and Organizational Psychology (6th ed.). $\quad$ Routledge. Retrieved from http://libgen.io/book/index.php?md5=39D625850FDDE8A9A4188D4AC64 9AB8D

Robbins, Stephen P., 2002. Prinsip-Prinsip Perilaku Organisasi, alih bahasa oleh Halida dan Dewi Sartika, Edisi Kelima, Erlangga

Robbins, Stephen. 2003. Organizational Behaviour, Tenth Edition (Perilaku Organisasi Edisi ke Sepuluh), Alih Bahasa Drs. Benyamin Molan. Jakarta: PT. Macanan Jaya Cemerlang

Santosa dan Ashari 2005 Budi Purbayu Santosa dan Ashari. 2005. Analisis Statistik dengan Microsoft Excel \& SPSS. Andi Offset. Yogyakarta.

Sarwono, 2007. Analisis Jalur untuk Riset Bisnis dengan SPSS, Andi Offset Yogyakarta

Sedarmaynti. 2001. Sumber Daya Manusia dan Produktivitas Kerja. Mandar Maju: Bandung

Soegandhi, V. M. (2013). PENGARUH KEPUASAN KERJA DAN LOYALITAS KERJA TERHADAP ORGANIZATIONAL CITIZENSHIP BEHAVIOR PADA KARYAWAN PT. SURYA TIMUR SAKTI JATIM. AGORA, $1(1), \quad 12 . \quad$ Retrieved from http://publication.petra.ac.id/index.php/manajemen-bisnis/article/view/302

Steers, R., Porter, Lyman. (1983). Motivational and Work Behavior, $3^{\text {rd }}$ edition. Tokyo: Mc. Graw Hill Book Company.

Suwatno dan Doni Juni Priansa, (2011). Manajemen SDM dalam Organisasi Publik dan Bisnis. Bandung : CV Alfabeta

Tjiptohadi Sawarjuwono, A. P. K. (2003). INTELLECTUAL CAPITAL: PERLAKUAN, PENGUKURAN DAN PELAPORAN (SEBUAH LIBRARY RESEARCH). Jurnal Akuntansi Dan Keuangan, 5(1), 35-57. https://doi.org/https://doi.org/10.9744/jak.5.1.pp.\%2035-57

Ulrich, D. (1997). Human Resource Champions (1st ed.). Massachusetts: Harvard Business School Press. Retrieved from http://libgen.io/book/index.php?md5=31143DF34FCFF1F49CECE38B74CE E441

Umam, Khaerul (2010). Perilaku Organisasi. Bandung: Pustaka Setia

Wibowo. 2007. Manajemen Kinerja. PT. Raja Grafindo Parsada: Jakarta.

Wright, P.M., Dunford, B.B., \& Snell, S.A. 2001. "Human Resources And The Resource-Based View Of The Firm" dalam Journal of Management, 27.

\section{Link:}

http://portalhr.com/survei/gawat-pekerja-di-indonesia-80-not-engaged-lantas-apasolusinya, diakses tanggal 18 Oktober 2017 http://www.tribunnews.com/bisnis/2012/09/18/loyalitas-karyawan-di-indonesiasangat-rendah. Diakses 18 Oktober 2017

https://forlap.ristekdikti.go.id, diakses 2 November 2017 